\title{
STUDI KEANEKARAGAMAN ARTHROPODA PADA LAHAN PERTANIAN TUMPANGSARI UNTUK INVENTARISASI PREDATOR PENGENDALIAN HAYATI DI KECAMATAN BUMIAJI KOTA BATU
}

Amania Amin*, Ibrohim, dan Hawa Tuarita

${ }^{1}$ Program Studi Biologi, FMIPA, Universitas Negeri Malang

*Corresponding author : amin_amania@yahoo.com

\begin{abstract}
ABSTRAK
Pertanian tumpangsari merupakan pola penanaman dua atau lebih tanaman yaitu tanaman semusim dan tanaman tahunan yang bertujuan dapat menekan populasi hama. Salah satu cara menekan populasi hama adalah dengan menggunakan musuh alami yang sebagian besar berasal dari Arthropoda. Terkait dengan hal tersebut dilakukan penelitian dengan tujuan untuk mengetahui: (1) indeks keanekaragaman, kemerataan, dan kekayaan Arthropoda pada lahan pertanian tumpangsari di Kecamatan Bumiaji Kota Batu; (2) jenis Arthropoda yang berpotensi sebagai predator pada lahan pertanian tumpangsari di Kecamatan Bumiaji Kota Batu; dan (3) ada tidaknya hubungan kondisi faktor abiotik dengan jumlah spesies Arthropoda di Kecamatan Bumiaji Kota Batu. Pengambilan Arthropoda dilakukan pada lahan pertanian tumpangsari brokoli umur 4 minggu dan apel yang sedang berbunga dengan metode pitfall trap untuk pengambilan Arthropoda yang aktif di permukaan tanah dan jaring serangga untuk pengambilan Arthropoda yang aktif ditajuk tumbuhan. Penelitian dilakukan pada bulan Agustus hingga September 2013. Analisis yang digunakan dalam penelitiaan ini yaitu menggunakan indeks keanekaragaman, kemerataan, dan kekayaaan; sedangkan analisis hubungan faktor abiotik dengan jumlah spesies menggunakan regresi linier berganda. Hasil penelitian ditemukan jenis Arthropoda yang teridentifikasi sebagai predator sebanyak 19 spesies, Nilai indeks keanekaragaman sebesar 2,73 yang termasuk dalam kategori sedang; indeks kemerataan sebesar 0,82 yang mendekati nilai 1 yang berarti memiliki kemerataan yang merata dan kondisi stabil; dan indeks kekayaan sebesar 4,72, ada hubungan antara faktor abiotik dengan jumlah spesies Arthropoda predator yaitu pada taraf signifikan $\mathrm{R}^{2}$ total sebesar $20,3 \%$ dan yang paling berpengaruh adalah suhu tanah dan kecepatan angin. Perlu dilakukan uji laboratorium Arthropoda predator hama pada tanaman brokoli dan tanaman apel.
\end{abstract}

Kata Kunci: Arthropoda, Predator, Keanekaragaman, Lahan Pertanian Tumpangsari. 


\section{PENDAHULUAN}

Pola tanam tumpangsari merupakan sistem penanaman tanaman antara tanaman semusim dengan tanaman tahunan. Penanaman dengan cara ini bisa dilakukan pada dua atau lebih jenis tanaman yang umurnya berbeda-beda. Untuk dapat melaksanakan pola tanam tumpangsari secara baik perlu diperhatikan beberapa faktor lingkungan yang mempunyai pengaruh diantaranya ketersediaan air, kesuburan tanah, sinar matahari (Subhan, 1988). Menurut Effendi (1976), penggunaan pola tanam tumpangsari dimaksudkan untuk meningkatkan pendapatan petani, menghindarkan kegagalan bagi satu jenis tanaman, dengan menambahkan satu atau lebih jenis tanaman lain yang mempunyai sifat yang kompatibel. Selanjutnya (Warsana, 2009), menyatakan bahwa pola tanaman tumpangsari ditujukan untuk mengantisipasi adanya organisme pengganggu tumbuhan dan mengurangi resiko serangan hama maupun penyakit. Sebaiknya ditanam tanaman yang mempunyai hama maupun penyakit berbeda, atau tidak menjadi inang dari hama maupun penyakit tanaman lain yang ditumpangsarikan, sehingga secara maksimal dapat menekan populasi hama.

Sentral pertanian yang salah satunya terletak di Kecamatan Bumiaji, Kota Batu terletak diketinggian 680-1.200 meter dari permukaan laut dan diapit oleh 3 buah gunung yang telah dikenal yaitu Gunung Panderman (2010 meter), Gunung Arjuna (3339 meter), Gunung Welirang (3156 meter). Kodisi topografi yang bergunung-gunung dan berbukit-bukit menjadikan Kota Batu bersuhu udara rata-rata 15-19 derajat Celsius (ProfilBatu, 2013). Kemiringan lereng pada lahan penelitian yang terletak di kecamatan Bumiaji masih berkisar berada pada kelas II yaitu $<8-15$ yang artinya landai. Pada Data Dinas Pertanian dan Kehutanan Kota Batu (2011), Kecamatan Bumiaji memiliki produksi dan luas lahan terbesar dibandingkan dengan kecamatan lainnya di Kota Batu dengan luas lahan 444,8 ha, produksi mencapai $6.733,5$ ton dan produktivitas sebesar 15 ton/ha.

Salah satu pola pertanian tumpangsarinya adalah menanam tanaman apel sebagai tanaman tahunan dan tanaman brokoli sebagai tanaman musiman. Apel merupakan salah satu komoditi yang mempunyai nilai ekonomi tinggi di kota Batu. Apel merupakan tanaman tahunan yang memiliki jenis hama seperti kutu daun hijau, tungau, spider mite, cambuk merah, ulat daun, serangga penghisap daun, ulat daun hitam, dan lalat buah (Nugroho,2011).

Kol bunga hijau atau Brokoli merupakan tanaman sayur famili Brassicaceae (jenis kol dengan bunga hijau) berupa tumbuhan berbatang lunak diduga berasal dari Eropa. Hama penting pada tanaman brokoli adalah ulat grayak (S. litura) dan ulat croci (Crocidolomia pavonana Fabricius) (Setiawati 2005). Rukmana (1995) menyebutkan bahwa hama penting lainnya yang menyerang tanaman brokoli antara lain ulat plutela (Plutella xylostella Linnaeus), ulat tanah (A. ipsilon), dan kutu daun (Aphis brassicae Linnaeus). Hama- 
hama pada tanaman brokoli dapat ditekan populasinya dengan cara mengendalikan hama menghunakan musuh alami, Musuh alami yang berperan penting dalam menekan populasi hama adalah predator dari filum Arthropoda. Syatrawati dan Ngatimin (2011) menyebutkan bahwa Arthropoda yang terdapat pada pertanaman brokoli adalah Formicidae, Carabidae, Cicindellidae,

Staphylinidae, Lycosidae, dan

Oxyopidae.

Potensi musuh alami Arthropoda predator sampai saat ini masih menjadi bahan kajian dan penelitian yang berkelanjutan. Penelitian ini bertujuan untuk mengetahui Indeks keanekaragaman, kemerataan, dan kekayaan Arthropoda pada lahan pertanian tumpangsari di Kecamatan Bumiaji Kota Batu, untuk mengetahui jenis Arthropoda yang berpotensi sebagai predator pada lahan pertanian tumpangsari di Kecamatan Bumiaji Kota Batu, dan untuk mengetahui ada tidaknya hubungan kondisi faktor abiotik dengan jumlah spesies Arthropoda di Kecamatan Bumiaji Kota Batu.

\section{METODE}

Penelitian ini merupakan penelitian deskriptif eksploratif, yang mendeskripsikan jenis-jenis Arthropoda, keanekaragaman, kemerataan, dan Kekayaan Arthropoda dan mengidentifikasi jenis-jenis Arthropoda sebagai predator agen pengendalaian hayati pada lahan pertanian tumpangsari di Kecamatan Bumiaji Kota Batu. Waktu penelitian dimulai pada bulan Agustus -
September 2013. Tempat penelitian dilakukan di lahan pertanian tumpangsari tanaman brokoli berumur 4 minggu dan tanaman apel saat berbunga di Kecamatan Bumiaji Kota Batu. Kegiatan identifikasi Arthropoda dilakukan di Laboratorium Ekologi Bio 109, Jurusan Biologi Fakultas Matematika dan Ilmu Pengetahuan Alam Universitas Negeri Malang.

Pengambilan sampel penelitian menggunakan metode pitfall trap dilakukan secara sistematis sesuai dengan luas lahan pertanian tumpangsari yaitu 100x40 meter dan pitfall trap dipasang sebanyak 150 plot secara teratur diantara tanaman tumpangsari tanaman brokoli berumur 4 minggu dan tanaman apel yang sedang berbunga. Pengambilan artrhopoda predator yang aktif di tajuk tumbuhan menggunakan jaring serangga. Pengambilan ini dilakukan pada titik di plot yang sama dengan pitfall trap. Pengambilan dilakukan pada masing-masing titik sebanyak 5 kali osilasi (ayunan jaring Arthropoda) secara kontinyu pada bagian tajuk tumbuhan, Setiap satu kali ayunan adalah kekiri dan kekanan. Pengambilan sampel dilakukan dari jam 07.00-11.00 WIB.

Hasil dari pengambilan sampel

penelitian dengan pitfall trap di masukkan ke dalam botol plakon dan sampel dari hasil tangkapan menggunakan jaring serangga dimasukkan ke dalam plastik selanjutnya dibawa ke laboratorium untuk diidentifikasi dengan bantuan buku identifikasi Borror (1992), Wenying (2000) dan untuk identifikasi sifat Arthropoda sebagai predator berdasarkan ciri morfologinya serta di 
cocokkan dengan hasil penelitian tentang Arthropoda yang berperan sebagai predator yang terdahulu.

Data dilakukan analisis yang diantaranya:

1. Indeks Keanekaragaman (Shannon-Wiener), $\mathrm{H}^{\prime}=-\sum \mathrm{Pi}$ $\ln \mathrm{Pi}$,

\section{HASIL PENELITIAN}

Jenis Arthropoda yang meliputi 28 spesies dari 19 famili yang disajikan pada tabel 1 . Arthropoda yang teridentifikasi sebagai predator

Tabel 1. Jenis Arthropoda yang ditemukan Pada Lahan Pertanian Tumpangsari Di Kabupaten Bumiaji Kota Batu
2. Indeks Kemeratan (Evennes), $E=\frac{H^{\prime}}{\ln . S}$

3. Indeks kekayaan (richness), $\mathrm{R}$ $=\mathrm{S}-1 / \mathrm{ln} \mathrm{N}$

4. Analisis Regresi Berganda (Linier) untuk mengetahui hubungan antara faktor abiotik dengan jumlah jenis Arthropoda predator yang ditemukan

ditemukan pada lahan pertanian tumpangsari brokoli dan apel adalah sebayak 19 spesies yang telah masuk kedalam jebakan pithfall dan terjaring alat jaring yang disajikan pada tabel 2 .

\begin{tabular}{llll}
\hline No. & Taksa & Genus & Famili \\
\hline 1 & Euryderus $s p$. & Euryderus & Carabidae \\
2 & Nebria lacustris & Nebria & \\
3 & Patrobus longicornis & Patrobus & \\
4 & Lebia $s p$ & Lebia & \\
5 & Platydema sp & Platydema & Tenebrionidae \\
6 & Naupactus cervinus & Naupactus & Curculionidae \\
7 & Otiorhynchus ovatus & Otiorhynchus & \\
8 & Oxypoda $s p$ & Oxypoda & Staphylinidae \\
9 & Carpelimus $s p$. & Carpelimus & \\
10 & Tachyusa $s p$. & Tachyusa & \\
11 & Anotylus $s p$ & Anotylus & \\
12 & Trochosa $s p$. & Trochosa & Lycosidae \\
13 & Lycosa $s p$. & Lycosa & \\
14 & Pardosa $s p$. & Pardosa & \\
15 & Sceliphron $s p$ & Sceliphron & Specidae \\
16 & Formica $s p$ & Formica & formicidae \\
17 & Elliptorhina $s p$ & Elliptorhina & Blattoidea \\
18 & Lithobius $s p$ & Lithobius & Lithobidae \\
19 & Microporus $s p$. & Microporus & Cydnidae \\
20 & Neocurtilla hexadactyla & Neocurtilla & Gryllotalpidae \\
21 & Atractomorpha sp & Atractomorpha & Acrididae \\
\hline
\end{tabular}




\begin{tabular}{llll}
\hline 22 & $\begin{array}{l}\text { Menochilus } \\
\text { sexmaculatus }\end{array}$ & Menochilus & Coccinellidae \\
23 & Archytas $s$. & Archytas & Tachinidae \\
24 & Rhagoletis $s p$. & Rhagoletis & Tephritidae \\
25 & Allograpta $s p$. & Allograpta & Syrphidae \\
26 & Drosophilla $s p$ & Drosophilla & Drosophilidae \\
27 & Gryllus $s p$ & Gryllus & Gryllidae \\
28 & Euborellia $s p$ & Euborellia & Anisolabididae \\
\hline
\end{tabular}

Tabel 2. Jenis Arthropoda yang teridentifikasi sebagai predator

\begin{tabular}{lll}
\hline No. & Taksa & Famili \\
\hline 1. & Euryderus $\mathrm{sp}$ & Carabidae \\
2. & Nebria lacustris & Carabidae \\
3. & Patrobus longicornis & Carabidae \\
4. & Lebia $\mathrm{sp}$ & Carabidae \\
5. & Oxypoda $\mathrm{sp}$ & Staphylinidae \\
6. & Carpelimus $\mathrm{sp}$ & Staphylinidae \\
7. & Tachyusa $\mathrm{sp}$ & Staphylinidae \\
8. & Anotylus $\mathrm{sp}$ & Staphylinidae \\
9. & Trochosa $\mathrm{sp}$ & Lycosidae \\
10. & Lycosa $\mathrm{sp}$ & Lycosidae \\
11. & Pardosa $\mathrm{sp}$ & Lycosidae \\
12. & Sceliphron $\mathrm{sp}$ & Sphecidae \\
Lanjutan tabel 2. & \\
\hline 13. & Formica $\mathrm{sp}$ & Formicidae \\
14. & Elliptorhina $\mathrm{sp}$ & Blattoidea \\
15. & Lithobius $\mathrm{sp}$ & Lithobidae \\
16. & Archytas $\mathrm{sp}$ & Tachinidae \\
17. & Euborellia $\mathrm{sp}$ & Anisolabididae \\
18. & Menochilus & Coccinellidae \\
& Sexmaculatus & \\
19. & Allograpta $\mathrm{sp}$ & Syrphidae \\
\hline
\end{tabular}

Indeks keanekaragaman Arthropoda predator pada Lahan pertanian tumpangsari brokoli dan apel sebesar 2,73, tersebut dikatakan indeks keanekaragaman Shanon-Wiener pada Lahan pertanian dikategorikan dengan keanekaragaman sedang. Indeks kemerataan (E) komunitas Arthropoda predator pada lahan pertanian tumpangsari brokoli dan apel memiliki nilai sebesar 0,82 . Hasil analisis indeks kemerataan yang didapatkan Lahan penelitian dengan nilai yang mendekati nilai satu yaitu yang dikategorikan bahwa Lahan pertanian tumpangsari brokoli umur 4 minggu dan tanaman apel dedang berbunga memiliki kemerataan komunitas Arthropoda predator yang merata dan dalam kondisi stabil. Nilai indeks Kekayaan 
(R) Arthropoda predator pada Lahan pertanian tumpangsari taanaman brokoli dengan tanaman apel didapatkan nilai sebesar 4,72. Data hasil penelitian secara lengakap disajikan pada tabel 3 .

Tabel 3. Jenis, nilai Indeks Keanekaragaman, Kemerataan dan Kekayaan Arthropoda Predator Pada Lahan Pertanian Tumpangsari Di Kabupaten Bumiaji Kota Batu

\begin{tabular}{|c|c|c|c|}
\hline NO. & Taksa & $\sum$ & $\mathbf{P i}$ \\
\hline 1. & Euryderus sp. & 3 & 0,010 \\
\hline 2. & Platydema sp & 42 & 0,137 \\
\hline 3. & Naupactus cervinus & 7 & 0,023 \\
\hline 4. & Otiorhynchus ovatus & 5 & 0,016 \\
\hline 5. & Nebria lacustris & 3 & 0,010 \\
\hline 6. & Patrobus longicornis & 9 & 0,029 \\
\hline 7. & Oxypoda sp. & 7 & 0,023 \\
\hline 8. & Carpelimus sp & 6 & 0,020 \\
\hline 9. & Tachyusa sp & 9 & 0,029 \\
\hline 10. & Sceliphron sp & 1 & 0,003 \\
\hline 11. & Lebia $s p$ & 50 & 0,163 \\
\hline 12. & Trochosa sp & 8 & 0,026 \\
\hline 13. & Lycosa sp. & 9 & 0,029 \\
\hline 14. & Pardosa sp. & 10 & 0,033 \\
\hline 15. & Formica sp & 52 & 0,170 \\
\hline 16. & Elliptorhina sp. & 3 & 0,010 \\
\hline 17. & Microporus sp. & 5 & 0,016 \\
\hline 18. & Lithobius sp & 5 & 0,016 \\
\hline 19. & $\begin{array}{l}\text { Neocurtilla } \\
\text { hexadactyla }\end{array}$ & 4 & 0,013 \\
\hline Lanjl & an tabel 3. & & \\
\hline 20. & Atractomorpha sp & 4 & 0,013 \\
\hline 21. & $\begin{array}{l}\text { Menochilus } \\
\text { sexmaculatus }\end{array}$ & 3 & 0,010 \\
\hline 22. & Archytas sp. & 2 & 0,007 \\
\hline 23. & Rhagoletis sp. & 2 & 0,007 \\
\hline 24. & Allograpta sp. & 4 & 0,013 \\
\hline 25. & Drosophilla sp & 38 & 0,124 \\
\hline 26. & Gryllus sp. & 7 & 0,023 \\
\hline 27. & Euborellia sp & 6 & 0,020 \\
\hline 28. & Anotylus sp & 2 & 0,007 \\
\hline & $\mathbf{H}^{\prime}$ & \multicolumn{2}{|c|}{2,73} \\
\hline & $\mathbf{E}$ & \multicolumn{2}{|c|}{$\mathbf{0 , 8 2}$} \\
\hline & $\mathbf{R}$ & \multicolumn{2}{|c|}{4,72} \\
\hline
\end{tabular}


Berdasarkan hasil analisis regresi didapatkan hasil bahwa ada korelasi antara kelembaban tanah, $\mathrm{pH}$ tanah, suhu tanah, intensitas cahaya dan kecepatan angin terhadap jumlah masing-masing spesies Arthropoda predator pada Lahan pertanian tumpangsari tanaman brokoli dengan tanaman apel dengan nilai $\mathrm{R}^{2}$ total sebesar 0.203. Ini menunjukkan bahwa ada hubungan antara faktor abiotik (suhu tanah, kelembaban tanah, intensitas cahaya, $\mathrm{pH}$ tanah dan kecepatan angin) dengan jumlah spesies Arthropoda predator di lahan pertanian tumpangsari brokoli dengan tanaman apel pada taraf signifikan $\mathrm{R}^{2}$ total sebesar $20,3 \%$.

Jenis-jenis Arthropoda yang ditemukan pada lahan pertanian tumpang sari tanmana brokoli dan tanaman apel yaitu 28 spesies dari 19 famili. Arthropoda yang berpotensi sebagai predator pada lahan pertanian tumpangsari brokoli umur 4 minggu dan tanaman apel sedang berbunga ditemukan sebanyak 19 spesies. Famili Arthropoda yang berperan sebagai predator yaitu Formicidae, Sclerosomatidae, Forficulidae, Carabidae, Salticidae, Lycosidae, Staphylinidae, Scolopendromorpha, dan Lithobiomorpha (Borror, 1992).

Pada penelitian yang telah dilakukan ditemukan famili Carabidae yang menurut Borror (1992) bersifat pemangsa serangga-serangga lain (predator) baik larva maupun imago. Kumbang dari famili Carabidae seringkali disebut pemburu ulat. Kumbang dewasa mampu memotong tubuh mangsanya dengan menggunakan mandibulatanya.
Kumbang dewasa umumnya aktif pada malam hari, memangsa serangga yang hidup di permukaan tanah, jarang ditemukan naik ke atas tanaman untuk mencari mangsa (Purnomo, 2010). Lebia sp; yang memiliki peranan sebagai predator yang sesuai dengan pernyataan Hinds dan Dew ( 1915) melaporkan Lebia sp sebagai predator pada tahap dewasa dari ulat grayak.Ulat grayak merupakan hama penting pada tanaman brokoli (Setiawati 2005).

Famili Staphylinidae sebagian besarnya memiliki peranan sebagai pemangsa (predator) pada telur, larva, pupa, beberapa kutu daun dan tungau. Trochosa sp, Lycosa sp, Pardosa sp merupakan famili Lycosidae yaitu Laba-laba serigala dan peloncat, Labalaba ini memakan ngengat, ulat dan serangga lain. Setelah menangkap serangga, laba-laba menyuntikkan racun yang melumpuhkan korban, kemudian mengisap cairan tubuh korban. Sceliphron sp dari famili Sphecidae bukan merupakan serangga sosial, tetapi merupakan pemangsa ulat Lepidoptera dan laba-laba (Purnomo, 2010). Formica sp ini banyak terdiri dari predator, semut merupakan musuh alami karena menyerang ulat dan beberapa macam hama lain, contohnya Helopeltis yaitu hama pada apel.

Famili Coccinellidae merupakan kumbang kubah berukuran kecil hanya berukuran sekitar 4-8 mm, tetapi kumbang kubah ini merupakan predator dari beberapa jenis kutu. Baik larva maupun imago dapat berperan sebagai predator, tetapi daya cari larva Cocci lebih tinggi dibandingkan pada saat dewasa. Famili Syrphidae 
merupakan predator dari hama pengerek batang, baik larva maupun dewasa dapat berperan sebagai predator. Predator Menochilus sexmaculatus merupakan musuh alami yang efektif dalam menekan hama kutu daun (Buriro, 1996).

Famili Anisolabididae merupakan jenis predator yang dapat memangsa segalanya dari telur, larva dan pupa. Salah satu dari famili Anisolabididae yang ditemukan dalam penelitian ini adalah Euborellia sp yang merupakan musuh alami dari ulat, larva, kumbang dan wereng.

Indeks keanekaragaman adalah perbandingan nilai spesies dengan nilai total seluruh spesies dalam suatu komunitas. Hasil nilai indeks keanekaragaman menggunakan indeks Shanon-Wiener, pada lahan pertanian tumpangsari tanaman brokoli dengan tanaman apel memiliki indeks keanekaragaman sebesar 2,73 (Tabel 4.4). Indeks keanekaragaman dalam penelitian ini menunjukkan bahwa Arthropoda pada lahan pertanian tumpangsari memiliki keanekaragaman sedang, penyebaran jumlah individu tiap spesies sedang dan kestabilan ekosistem sedang.

Keanekaragaman Arthropoda yang tergolong sedang pada lahan pertanian tumpangsari brokoli dan apel karena itu keberadaan Arthropoda predator tidak begitu beranekaragam, hal itu dikarenakan adanya faktor tekanan lingkungan seperti kelembaban tanah, suhu tanah, $\mathrm{pH}$ tanah yang membuat organisme menjadi terganggu dan tidak menempati ekosistem tersebut secara optimum Seperti yang di jelaskan oleh Darmawan dkk (2005), bahwa keanekaragaman cenderung akan rendah pada ekosistem yang secara fisik terkendali, atau mendapatkan tekanan lingkungan. Penelitian yang dilakukan Mubarrak (2006) yang menyimpulkan jumlah ordo dan famili arthropoda tanah lebih beragam pada pertanaman tumpangsari dibandingkan dengan pertanaman monokultur. Hal ini menunjukkan bahwa arthropoda tanah lebih menyenangi kondisi lahan dengan beragam tanaman dan mempunyai kelembaban cukup.

Hasil analisis selanjutnya yaitu indeks kemerataan. Indeks kemerataan adalah keberadaan individu masingmasing spesies yang ditemukan pada suatu komunitas. Nilai indeks kemerataan Artropoda pada lahan pertanian tumpangsari brokoli dengan apel diperoleh sebesar 0,82 (Tabel 4.4). Hasil analisis indeks kemerataan yang didapatkan Lahan penelitian dengan nilai yang mendekati nilai satu yaitu yang dikategorikan bahwa Lahan pertanian tumpangsari memiliki kemerataan komunitas Arthropoda predator yang merata dan dalam kondisi stabil. Hal ini juga di pengaruhi oleh keanekaagaman Arthropoda yang termasuk dalam kategori sedang, sehingga kemerataan Arthropoda pada lahan pertanian menjadi stabil dan merata. Hal ini sesuai dengan pernyataan Odum (1993) yang mengatakan bahwa keanekaragaman identik dengan kestabilan suatu ekosistem, yaitu jika keanekaragaman suatu ekosistem tinggi, maka kondisi ekosistem tersebut cenderung stabil.

Kekayaan (R) Arthropoda pada lahan pertanian tumpangsari brokoli dengan tanaman apel sebesar 4,72 
yang tergolong dalam kekayaan jenis sedang. Hal ini Berdasarkan Magurran (1988) besaran $\mathrm{R}<3,5$ menunjukkan kekayaan jenis tergolong rendah, $\mathrm{R}=3,5-5$ menunjukkan kekayaan jenis tergolong sedang dan $\mathrm{R}>5$ kekayaan jenis tergolong tinggi.

Keanekaragaman, kemerataan, dan kekayaan Arthropoda pada lahan pertanian tumpangsari juga dipengaruhi oleh faktor biotik dan abiotik. Faktor biotik dan abiotik secara bersama-sama dalam suatu ekosistem menentukan kehadiran, kelimpahan, dan penampilan organisme. Faktor biotik tersebut meliputi pertumbuhan populasi, interaksi antar spesies yang berupa kompetisi dan predator, sedangkan faktor abiotik meliputi kelembaban, suhu, ketinggian tempat, dan $\mathrm{pH}$ yang merupakan pendukung bagi kehidupan hewan (Andayani, 2001).

Hasil analisis regresi berganda antara hubungan faktor abiotik dengan jumlah spesies pada lahan pertanian tumpangsari dari taraf signifikan didapatkan pengaruh sebesar 20,3\% dan yang paling mempengaruhi Arthropoda pada lahan pertaian tumpangsari adalah kecepatan angin dan suhu tanah. Kecepatan angin berperan dalam memebantu penyebaran Arthropoda, terutama bagi Arthropoda yang berukuran kecil dan Suhu yang sesuai akan mempengaruhi pertumbuhan organisme lain yang menjadi sumber makanan bagi Arthropoda. Suhu menjadi berpengaruh karena mempengaruhi pertumbuhan serangga tersebut, dikarenakan serangga bersifat ektoterm yang berarti suhu berdampak besar dalam pertumbuhan individu.
Pada umumnya pertumbuhan serangga berkolerasi dengan suhu, walau bagaimanapun kekuatan hubungan antara habitat dengan spesies bersifat spesifik. Suhu dipengaruhi adanya kelembaban dalam mengatur suhu karena terjadi interaksi yang sangat erat hingga dianggap sebagai bagian yang sangat penting dari kondisi cuaca dan iklim (Kramadibrata, 1990). Dalam aktivitasnya hewan yang tergolong dalam filum Arthropoda dapat dipengaruhi oleh suhu yang memiliki kisaran tertentu dalam setiap masingmasing spesiesnya. Pada suhu tertentu aktivitas Arthropoda tinggi, akan tetapi pada suhu lain akan berkurang (menurun). Pada umumnya kisaran suhu yang efektif adalah sebagai berikut: suhu minimum $15^{\circ} \mathrm{C}$, suhu optimum $25^{\circ} \mathrm{C}$, dan suhu maksimum $45^{\circ} \mathrm{C}$ (Jumar, 2000:92).

\section{SIMPULAN}

Berdasarkan hasil penelitian dapat disimpulkan Arthropoda yang berpotensi sebagai predator pada lahan pertanian tumpangsari brokoli dan apel yang adalah Sebanyak 19 spesies dari 9 famili. Indeks keanekaragaman (H') Arthropoda predator pada lahan pertanian tumpangsari brokoli dengan apel yaitu sebesar 2,73 yang dikategorikan dengan keanekaragaman sedang. kemerataan spesiesnya kategorikan tinggi (merata dan stabil) dengan nilai mendekati 1 yaitu sebesar 0,82 dan Kekayaan Arthropoda predator sebesar 4,72 yang tergolong dalam kekayaan jenis sedang. Ada hubungan antara faktor abiotik dengan 
jumlah spesies Arthropoda pada lahan pertanian tumpangsari yaitu pada taraf signifikan $\mathrm{R}^{2}$ total sebesar $20,3 \%$ dan faktor abiotik yang paling memberikan pengaruh adalah kecepatan angin dan suhu tanah.

Berdasarkan simpulan di atas saran mengenai uji laboratorium Arthropoda predator hama pada tanaman brokoli dan tanaman apel.

\section{DAFTAR PUSTAKA}

Andayani, L. 2001. Studi

Keanekaragaman Fauna Tanah

Pascaerupsi Gunung Kelud

Kecamatan Ngancar Kediri.

Skripsi tidak di terbitkan.

Malang: FMIPA UM.

Borror, T.J. 1992. Pengenalan Pelajaran Serangga.

Diterjemahkan Oleh Gadjah Mada University. Yokyakarta: Gadjah Mada University Press.

Buriro, A.S. 1996. Studies On Varietal

Risistance Of Wheat Cultivars

to Aphids (Aphididae:

Homoptera). Ph.D Thesis,

Sindh Agric. Univ. Tando Jam,

Pakistan, pp:223.

Darmawan, A. Tuarita, H. Ibrohim.

2005. Ekologi Hewan. Malang:

UM Press

Dinas Pertanian dan Kehutanan Kota

Batu. 2011. Rekapitulasi Data

Dasar Pertanian Kecamatan

Batu. Kota Batu.

Effendi, S.S. 1976. Pola bertanam. LP3 Bogor.

Magurran, Anne E. (1988). Ecological

Diversity and Its Measurement.

Princeton: Princeton University

Press.
Jumar. 2000. Entomologi Pertanian. Jakarta: Rineka Cipta.

Kramadibrata, I. 1990. Pengantar

Ekologi Hewan. Bandung : Jurusan Biologi FMIPA ITB.

Mubarrak, A. 2006. Perkembangan Hama Dan Penyakit Tanaman Kubis Pada Tiga Sistem Budi Daya. Thesis tidak diterbitkan. Bogor: ITB

Odum, E. 1993. Dasar-Dasar Ekologi. Yogyakarta: UGM Press.

Profil Kota Batu. 2013. (Online) (http://www.batukota.go.id/pro fil/ diakses tanggal 3 Februari 2013).

Purnomo, Hari. 2010. Pengantar Pengendalian Hayati. Yogyakarta: ANDI

Rukmana R. 1995. Budidaya Kubis Bunga dan Broccoli. Yogyakarta: Kanisius.

Setiawati, Uhan TS, Somantri A. 2005. Parasitoid E. argenteopilosus sebagai agens pengendali hayati hama $H$. armigera, $S$. litura, dan C. pavonana pada tumpangsari tomat dan brokoli. J.Hort. 15(4): 279-287.

Subhan, 1988. Pengaruh tumpangsari jagung dan kentang terhadap pertumbuhan dan hasil pada musim kemarau. Bul. Penel. Hort.16(3):58 - 62.

Syatrawati, Ngatimin SN. 2011. Peranan gulma berbunga terhadap kelimpahan arthropoda tanah pada pertanaman kubis di Sulawesi. Makassar: Politeknik Pertanian Negeri Pangkep, Universitas Hassanudin. 
Warsana. 2009. Introduksi Teknologi Tumpangsari Jagung dan

Kacang Tanah. Sinar Tani 25

Feb - 3 Maret 2009 No. 3292.

BPTP Jawa Tengah.
Wenying, Yin. 2000. Pictorial Keys To Soil Animals Of China. Beijing: Science Press. 